\title{
A Comparative Study of the Efficacy of Intraumbilical Oxytocin and Intravenous Methyergometrine in the third Stage Bleeding
}

\author{
Authors \\ Dr Deepthy Balakrishnan, Dr P Leelamma
}

\begin{abstract}
Aim: To compare the efficacy of intraumbilical Oxytocin and intravenous Methyl ergometrine in active management of third stage of labour.

Material and Methods: This is a prospective study of 100 cases of singleton low risk pregnancies where 50 cases were allotted at random to group I which included patients who received intraumbilical Oxytocin 10 $I U$ immediately after delivery of the baby. Injection Methylergometrine $(0.2 \mathrm{mg})$ was given intravenously at the delivery of anterior shoulder of the baby to women in Group 2. Outcome measures were the duration of third stage, amount of blood loss, post-delivery hemoglobin and side effects in both groups.

Statistical analysis: The statistical constants like mean, standard deviation and percentage were calculated. The hypothesis formulated was tested statistically by using chi-square test.

Results: There was no statistically significant difference in mean duration of third stage of labour, mean blood loss, post-delivery hemoglobin, need for additional uterotonics or in side effects between the two groups.

Conclusion: Intraumbilical oxytocin is as effective as methylergometrine in reducing the duration of third stage of labour and blood loss and is useful in prevention of postpartum hemorrhage.

Keywords: Postpartum hemorrhage, Active management of third stage of labor, blood loss, duration of third stage.

Key message: Intraumbilical oxytocin can be used in active management of third stage especially in patients with no intravenous access and in high risk patients.
\end{abstract}

\section{Introduction}

Postpartum hemorrhage is a major cause of maternal mortality and morbidity across the world especially in developing and underdeveloped countries $^{(1)}$. It was estimated that in 2015, roughly 303000 women died during and following pregnancy and childbirth ${ }^{(2)}$. In India, where maternal mortality rate is 174 / 100,000 live births (2015 CIA World Factbook), reducing PPH remains as a major challenge. The most effective intervention in preventing atonic $\mathrm{PPH}$, which is a leading cause of maternal death, is active management of third stage of labor ${ }^{(3)}$. It has been proven that $40 \%$ of cases of postpartum hemorrhage can be prevented by active management of third stage of labor ${ }^{(4)}$. Several Uterotonic drugs like Oxytocin,

Methylergometrine, Syntometrine, Prostaglandin analogues in varying doses and different routes of administration had been studied yielding different results ${ }^{(5-9)}$. 
This randomized study was conducted to compare Methylergometrine and Intraumbilical Oxytocin in terms of efficacy, duration of third stage, blood loss, adverse effects and reduction in incidence of postpartum hemorrhage and retained placenta.

\section{Settings}

This was a prospective study conducted in the department of obstetrics and gynecology, SAT hospital, Trivandrum, Kerala, India for a period of 6 months.

\section{Material and Methods}

It was conducted on 100 women who went in to spontaneous labor with no risk factors for $\mathrm{PPH}$. All patients included in the study delivered vaginally.

The eligible women who gave informed consent were assigned to 2 groups at a random of 50 in each group. Women with even inpatient number were allotted to Group 1 and odd inpatient number allotted to Group II. Group 1 included women who received intraumbilical oxytocin immediately after the delivery of the baby (i.e.10 units of oxytocin diluted in $20 \mathrm{ml}$ of normal saline injected in to umbilical vein). Group II comprised women who received injection methyl-ergometrine 0.2 $\mathrm{mg}$ intravenous at the time of delivery of the anterior shoulder. The cord was clamped and cut immediately after the delivery of the baby. Placenta was delivered by controlled cord traction of the umbilical cord. Blood loss was noted by measuring the blood collected in a basin and by using preweighed pads and gauze. None of the patients were induced and had gone in to spontaneous labour and were not augmented with oxytocin.

\section{Inclusion Criteria}

1) Singleton

2) Cephalic pregnancies

3) Spontaneous onset of labor

4) No contraindication for Oxytocin/Methyl ergometrine

5) No known risk factor for PPH.
6) Parity $\leq 2$

7) Period of gestation $>37$ weeks

\section{Exclusion Criteria}

1) Previous C.S

2) Multiple pregnancy

3) Anemia $\{\mathrm{Hb}<9 \mathrm{~g} \%\}$

4) High risk pregnancies

5) Instrumental delivery

6) Previous history of PPH

\section{Outcomes}

1) Time taken for separation of the placenta was noted.

2) Post delivery hemoglobin

3) Amount of blood loss.

4) Need for additional uterotonics.

5) Need for manual removal of placenta or subsequent surgical evacuation of retained products

6) Need for blood transfusion

7) Adverse effects of the uterotonics used.

\section{Statistical Analysis}

The data collected were entered in to master chart and statistical tables were constructed in order to compare the two groups. The statistical constants like mean, standard deviation and percentage were computed. The hypothesis formulated was tested statistically by using chisqu are test in the case of quantitative data. Diagrams and charts were drawn where ever necessary to substantiate the important findings. All statistical commutations were done with the help of SPSS computer package. 


\section{Results}

Table 1 Demographic profile of women.

\begin{tabular}{|c|c|c|c|}
\hline Characteristics & Group I [oxytocin] & Group II [methergine] & Statistical \pm analysis \\
\hline $\begin{array}{l}\text { Age in years } \\
<20 \\
20-29 \\
>30 \\
\end{array}$ & $\begin{array}{c}3(6 \%) \\
44(88 \%) \\
3(6 \%) \\
\end{array}$ & $\begin{array}{c}4(8 \%) \\
43(86 \%) \\
3(6 \%) \\
\end{array}$ & $\begin{array}{l}X^{2}=1.01 \\
P>0.05\end{array}$ \\
\hline $\begin{array}{l}\text { Parity } \\
\text { Primi } \\
\text { multi }\end{array}$ & $\begin{array}{l}26(52 \%) \\
24(48 \%)\end{array}$ & $\begin{array}{l}31(62 \%) \\
19(38 \%)\end{array}$ & $\begin{array}{l}x^{2}=1.01 \\
P>0.05\end{array}$ \\
\hline $\begin{array}{l}\text { Booking status } \\
\text { Booked } \\
\text { Referred }\end{array}$ & $\begin{array}{c}49(98 \%) \\
1(2 \%)\end{array}$ & $\begin{array}{c}50(100 \%) \\
0\end{array}$ & $P>0.05$ \\
\hline $\begin{array}{l}\text { Education } \\
\text { High school } \\
\text { college }\end{array}$ & $\begin{array}{l}21(42 \%) \\
29(58 \%)\end{array}$ & $\begin{array}{l}23(44 \%) \\
27(56 \%)\end{array}$ & $\begin{array}{c}\mathrm{x}^{2}=0.16 \\
\mathrm{P}>0.05\end{array}$ \\
\hline $\begin{array}{l}\text { Socioeconomic status } \\
\text { High } \\
\text { Middle } \\
\text { poor }\end{array}$ & $\begin{array}{c}3(6 \%) \\
25(50 \%) \\
22(44 \%) \\
\end{array}$ & $\begin{array}{c}2(4 \%) \\
31(62 \%) \\
17(34 \%) \\
\end{array}$ & $\begin{array}{c}\mathrm{x}^{2}=1.48 \\
\mathrm{P}>0.05\end{array}$ \\
\hline $\begin{array}{l}\text { Occupation } \\
\text { Housewife } \\
\text { Domestic servants } \\
\text { Office work } \\
\text { others }\end{array}$ & $\begin{array}{c}38(76 \%) \\
5(10 \%) \\
5(10 \%) \\
2(4 \%) \\
\end{array}$ & $\begin{array}{c}42(84 \%) \\
4(8 \%) \\
3(6 \%) \\
1(2 \%)\end{array}$ & $\begin{array}{c}x^{2}=1.16 \\
P>0.05\end{array}$ \\
\hline $\begin{array}{l}\text { Distribution according to } \\
\text { blood group } \\
\mathrm{A} \\
\mathrm{B} \\
\mathrm{AB} \\
\mathrm{O}\end{array}$ & $\begin{array}{c}6(12 \%) \\
15(30 \%) \\
6(12 \%) \\
23(46 \%)\end{array}$ & $\begin{array}{c}8(16 \%) \\
15(30 \%) \\
3(6 \%) \\
24(48 \%)\end{array}$ & $\begin{array}{l}x^{2}=1.3 \\
P>0.05\end{array}$ \\
\hline
\end{tabular}

There were no significant differences in mean age, parity, socioeconomic status, occupation, education, booking status, distribution of blood group among the two groups.

Table 2 Duration of third stage

\begin{tabular}{|l|c|c|c|c|}
\hline $\begin{array}{l}\text { Duration of third stage } \\
(\mathrm{min})\end{array}$ & $\begin{array}{c}\text { Group I } \\
\text { oxytocin }\end{array}$ & $\begin{array}{c}\text { Group } \\
\text { methergine }\end{array}$ & $\mathrm{Z}$ & $\mathrm{P}$ \\
\cline { 1 - 3 } Mean & 4.75 & 4.54 & \multirow{2}{*}{1.16} & $\mathrm{P}>0.05$ \\
\hline SD & 1.16 & 0.49 & \\
\hline
\end{tabular}

Mean duration of third stage of labor in the difference between the oxytocin and methergine oxytocin group was $4.75 \pm 1.16$ while in the group were not significant but both were equally methergine group it was $4.54 \pm 0.49$. The effective in reducing the third stage of labor.

Table 3 Amount of blood loss

\begin{tabular}{|l|c|c|c|c|}
\hline $\begin{array}{l}\text { Blood loss in third stage } \\
(\mathrm{ml})\end{array}$ & $\begin{array}{c}\text { Group I } \\
\text { oxytocin }\end{array}$ & $\begin{array}{c}\text { Group } \\
\text { methergine }\end{array}$ & $\mathrm{Z}$ & $\mathrm{P}$ \\
\cline { 1 - 3 } 0 & 159 & 164.8 & \multirow{2}{*}{$\mathrm{P}>0.05$} \\
\hline SD & 83.6 & 79.2 & & \\
\hline
\end{tabular}


Mean blood loss in oxytocin group was $159 \pm$ $83.6 \mathrm{ml}$ and mean blood loss in methergine group was $164.8 \pm 79.2 \mathrm{ml}$. The difference between the two groups was statistically insignificant.

Table 4 Effect on hemoglobin

\begin{tabular}{|l|c|c|c|}
\hline Hb level after delivery & $\begin{array}{c}\text { Group I } \\
\text { oxytocin }\end{array}$ & $\begin{array}{c}\text { Group II } \\
\text { methergine }\end{array}$ & \\
\hline Mean & 11.1 & 10.8 & \multirow{2}{*}{1.84} \\
\hline SD & 0.96 & 0.66 & \\
\hline
\end{tabular}

The mean $\mathrm{Hb} \%$ in the oxytocin group was $11.1 \pm 0.96$ and in the methergine group was $10.8 \pm 0.66$. The difference was statistically insignificant.

Table 5 Need for additional oxytocics

\begin{tabular}{|l|c|c|c|}
\hline Group & Number & Percentage & total \\
\hline I [oxytocin] & 1 & $2 \%$ & 50 \\
\hline II[methergine] & 1 & $2 \%$ & 50 \\
\hline
\end{tabular}

No patient in both groups had blood loss more for blood transfusion in both the groups. None of than $500 \mathrm{ml}$ and $2 \%$ of patients in both groups needed additional uterotonics. There was no need the patients had retained placenta.

Table 6 Associated side effects in both groups

\begin{tabular}{|l|c|c|c|}
\hline Variable & Group I & Group II & Statistical significance \\
\hline pulse rate after delivery & $78.52 \pm 3.7$ & $78.4 \pm 4.04$ & $\mathrm{P}>0.05$ \\
\hline Systolic BP after delivery & $114.5 \pm 5.13$ & $114.6 \pm 8.4$ & $\mathrm{P}>0.05$ \\
\hline Diastolic BP after delivery & $72.8 \pm 4.9$ & $71.8 \pm 4.3$ & $\mathrm{P}>0.05$ \\
\hline
\end{tabular}

Values are given as mean \pm SD unless otherwise indicated; Significant at $\mathrm{p}<0.05$; Blood pressure measured in $\mathrm{mm} \mathrm{Hg}$

There was no significant difference between the effect of oxytocin or methergine on pulse rate or on systolic or diastolic BP of patients.

\section{Discussion}

Active management of third stage of labor is recommended by WHO as a method of prevention of postpartum hemorrhage. It includes use of uterotonics following the birth of the baby; controlled cord traction followed by uterine massage and delayed cord clamping. This is of profound importance in low resource settings (10). There is still no agreement regarding the type and route of administration of uterotonics in the management of third stage of labor even though intramuscular oxytocin was recommended by world health organization.

In this study we have compared methyl ergometrine which has been used conventionally in active management of third stage against intraumbilical oxytocin. Golan et al proposed that injection of intraumbilical oxytocin leads to high concentration of oxytocin in the uterine wall and may be the cause of rapid placental expulsion ${ }^{(13)}$. Intraumbilical oxytocin is hence a useful alternative in patients in whom ergometrine is contraindicated and in those cases where intravenous fluids need to be restricted ${ }^{(12)}$.

In the study conducted by Athavale et al in India, where three groups of patients were given intraumbilical oxytocin, normal saline and methyl ergometrine each respectively, it was found that the expulsion of the placenta was rapid in the group which received intraumbilical oxytocin as compared to the group treated with normal saline but not with methylergometrine ${ }^{(11)}$.. In the present study, there was no statistically significant difference between the two groups with regard to maternal age and parity. Mean duration of third stage of labor in the intraumbilical oxytocin group was $4.75 \pm 1.16$ while in the methergine group, it was $4.54 \pm 0.49$. The difference in the time of separation of placenta between intraumbilical oxytocin and methergine group were not 
statistically significant but both were equally effective in reducing the third stage of labor which was similar to the previous study ${ }^{(11)}$. In another randomized control trial by Güngördük $\mathrm{K}$ et al, the third stage of labor was significantly shorter in the intraumbilical oxytocin group than in the placebo group (4.5+/-1.6 minutes compared with $7.9+/-3.4$ minutes, respectively; $\mathrm{P}<.001)^{(14)}$

The mean estimated blood loss was significantly lower in women treated with intraumbilical oxytocin compared with women in the placebo group (195.3+/-81.0 ML compared with 288.3+/134.1 ML, respectively; $\mathrm{P}<.001)^{(14)}$. In our study, mean blood loss in the intraumbilical oxytocin group was $159 \pm 83.6 \mathrm{ml}$ and mean blood loss in methergine group was $164.8 \pm 79.2 \mathrm{ml}$. The difference between the two groups was statistically insignificant. In another study by Reddy V V et al, pregnant women were randomized to receive intravenous oxytocin after delivery of the placenta or intraumbilical oxytocin immediately after cord clamping. Those who had intraumbilical oxytocin had a shorter third stage (4.1 versus 9.4 minutes) and less measured blood loss $(135$ versus $373 \mathrm{ml})$ compared to intraumbilical oxytocin.

The drop in hemoglobin was comparable in patients receiving intra-umbilical oxytocin and methylergometrine according to the study by Athavale et al and there was lower drop in the hematocrit (3.9\% versus $6.2 \%$ ) in the study by Reddy V V et al in the intraumbilical group compared to the IV oxytocin group. Similarly, in our study, the mean hemoglobin in the oxytocin group was $11.1 \pm 0.96$ and $10.8 \pm 0.66$ in the methergine group and the difference was statistically insignificant. Measurement of hemoglobin after delivery is a more objective method of assessing the amount of blood loss and also for planning intervention.

The percentages of placentas remaining undelivered beyond 15 minutes were $0 \%$ in the intraumbilical oxytocin group and $4.4 \%$ in the placebo group ${ }^{(14)}$ which was similar in our study as none of the patients had retained placenta.
In a study conducted in India by Ajantha Boopathi et al ${ }^{(16)}$, where intramuscular 10 units of oxytocin within one minute of birth of the baby was compared to $0.2 \mathrm{mg}$ of intravenous methylergometrine given at the time of delivery of anterior shoulder, there was a statistical increase in both systolic and diastolic blood pressure in the ergometrine group. In our study, no significant increase in blood pressure was noted.

It was concluded that intraumbilical oxytocin is as effective as methyl ergometrine in third stage of labour in preventing post partum bleeding without an increase in side effects. Oxytocin given at a dose of 10 units intraumbilically is technically easier to use and can be used in situations where intravenous access is unavailable. Oxytocin is very safe to use with least adverse effects and can be used even in high risk women. It can be used even in hypertensive women and in those with cardiovascular disease. The limitation of our study is the small sample size and further studies with larger number of subjects are needed.

\section{Conclusion}

The use of intraumbilical oxytocin for active management of the third stage of labor has significantly reduced postpartum blood loss and the duration of the third stage. Methylergometrine and Oxytocin have been used for a long time in markedly different doses and routes of administration with varying success. This study has shown that both methylergometrine and oxytocin were equally efficacious. However intraumbilical Oxytocin had other advantages in the form of ease of administration and lesser contraindications for usage. It is concluded that Intraumbilical oxytocin is as effective as prophylactic methyl ergometrine in the active management of the third stage of labour.

\section{References}

1. Abou ZC, Wardlaw T. Maternal mortality in 2000: Estimates developed by WHO, UNICEF and UNFPA. Geneva: World Health Organization. 2000. 
2. Maternal mortality: World health organization: Fact sheet. Updated on November 2016.

3. Mathai M, Gülmezoglu A, Hill S. WHO recommendations for the prevention of postpartum hemorrhage.Geneva: WHO Document Production Services; 2007. pp. 4-5.

4. Soltan $\mathrm{MH}$, El-Gendi E, Imam $\mathrm{HH}$, et al. Different doses of sublingual misoprostol versus methylergometrine for the prevention of atonic postpartum hemorrhage. Int J Health Sci (Qassim) 2007;1(2):229-23

5. Dumoulin, J.G. (1981) A Reappraisal of the Use of Ergometrine. Journal of Obstetrics and Gynecology, 1, 178-181.

6. Embrey, M.P. (1961) Simultaneous Intramuscular Injection of Oxytocin and Ergometrine: A tocographic Study. BMJ, 1, 1737-1738.

7. McDonald, S., Prendville, W.J. and Elbourne, D. (2001) Prophylactic Syntometrine versus Oxytocin for Delivery of the Placenta.

8. Suellen, M., et al. (2004) A Cochrane Review Metaanalysis. New Advances for Low-Resource Settings: Uterotonics for Prevention of Postpartum Hemorrhage. Journal of Midwifery \& Women's Health, 49, 283-292.

9. Bugalho, A., Daniel, A., Faundes, A. and Cunha, M. (2001) Misoprostol for Prevention of Postpartum Hemorrhage. International Journal of Gynecology Obstetrics, 73, 1-6. Mudaliar AL Causation and stages of labour.

10. Mudaliar and Menon's Clinical Obstetrics, Editors Gopalan S, Rathnakumar S, Jain V. 12th Edition.Hyderabad Universities Press (India) Pvt Ltd: 2015:94-6.

11. Athavale R D, Nerurkar N M, Dalvi S A, Bhattacharya M S. Umbilical vein oxytocin in the management of third stage of labour. J Postgrad Med 1991; 37:219.
12. Chestnut D, Oxytocin Wilcox LL. Influence of umbilical vein administration of in the third stage of labour: a randomized double blind placebo -controlled study.Amer J obstet \& gynecolo 1987; 157:160-162.

13. Golan A, (Baruch) Lidor AL, Wexler S, David MP. A new method for management of the retained placenta. Amer J Obstet \& Gynecol 1983; 146:708-709.

14. Güngördük K, Asicioglu O, Besimoglu B, Güngördük $\mathrm{OC}$, Yildirm $\mathrm{G}$, Ark $\mathrm{C}$, Tekirdağ AI. Using intraumbilical vein injection of oxytocin in routine practice with active management of the third stage of labor: a randomized controlled trial. Obstet Gynecol. 2010 Sep; 116(3):619-24.

15. Reddy Virginia V. et al Effect of umbilical vein oxytocin on puerperal blood loss and length of the third stage of labor. American Journal of Obstetrics \& Gynecology, Vol. 160, Issue 1, 206 - 208

16. Boopathi A, Nayak S, Rao And Rao B. (2014) Oxytocin Versus Methyergo-metrine In The Active Management Of Third Stage Of Labour. Open journal Of Obstetrics and gynecology.4, 666-671. 